\title{
Descrição inédita de Fannia sp. (Diptera: Fanniidae), como vetor dos ovos de Dermatobia hominis (Diptera: Cuterebridae) em Seropédica, $\mathbf{R J}$
}

\author{
New report on Fannia sp. (Diptera: Fanniidae), as a vector of Dermatobia \\ hominis (Diptera: Cuterebridae) eggs in Seropédica county, RJ.
}

\author{
Virginio Pereira da Silva Junior, ${ }^{*}$ André de Souza Leandro, ${ }^{*}$ Gonzalo Efrain Moya Borja*
}

\begin{abstract}
Resumo
Descreve-se a ocorrência inédita de um exemplar fêmea de Fannia sp., capturado em Seropédica, Rio de Janeiro, carreando 10 ovos de Dermatobia hominis, no lado esquerdo do abdômen. O exemplar encontrava-se pousado sobre um bovino, sendo capturado com rede entomológica.
\end{abstract}

Palavras-chave: Dermatobia hominis; berne; vetor; Fannia sp.

Fannia sp. (Diptera: Fanniidae) (Robineau- Desvoidy, 1830) tem sido descrita como veiculadora dos ovos de Dermatobia hominis (Diptera: Cuterebridae) (Linnaeus Jr., 1781) em várias partes do Brasil. Artigas e Serra (1965) publicaram uma lista de vetores onde na família Fanniidae citaram as seguintes espécies: $F$. heydenii, $F$. penicillaris, F. scalaris, F. petrocchiae $e$ Fannia sp. Guimarães et al. (1983) apresentaram uma lista de vetores contendo estas espécies. Paloschi et al. (1984), em Santa Catarina, citaram Fannia sp. como vetora dos ovos de $D$. hominis no Planalto Catarinense. Ribeiro et al. (1985), no Rio Grande do Sul, capturaram 93 espécies do gênero Fannia portando ovos, variando o número de ovos de 2 a 41 , com média de 18,8. Oliveira (1986), capturando dípteros em São Paulo, coletou Fannia sp.com ovos, assim como Kasai et al. (1990). Brum et al. (1996) descreveram pela primeira vez, no Rio Grande do Sul, Fannia punctipennis carreando

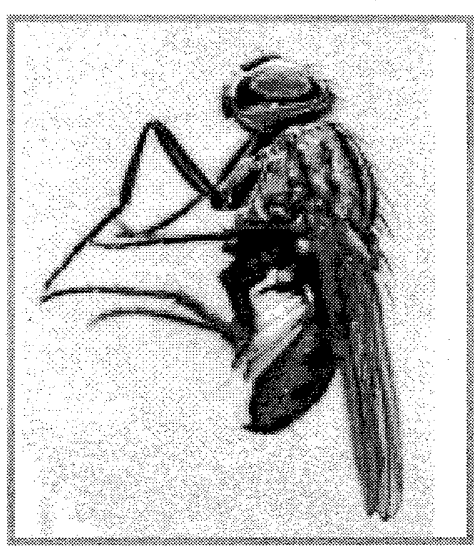

Figura 1: Fannia sp. portando ovos de Dermatobia hominis ovos de $D$. hominis. Eles capturaram três exemplares portando 8,18 e 23 ovos.

Descreve-se, pela primeira vez, um caso de veiculação dos ovos de Dermatobia hominis por Fannia sp.em Seropédica, Rio de Janeiro. O espécimen foi capturado com rede entomológica, pousado sobre um bovino que se encontrava em área de pastagem, no campus da Universidade Federal Rural do Rio de Janeiro. O pasto era composto de gramíneas rasteiras, próximo a um córrego. A aproximadamente $500 \mathrm{~m}$ do local da coleta, observara-se uma floresta de eucalipto.

A coleta foi realizada no mês de junho, em dia de sol, onde a temperatura encontravase a $21,8^{\circ} \mathrm{C}$ e umidade relativa de $52,7 \%$, registrados pela Estação Meteorológica da Pesagro-Rio, localizada a aproximadamente $2.000 \mathrm{~m}$ do local. O exemplar foi identificado no Laboratório de Diptera do Museu Nacional no Rio de Janeiro, sendo uma espécie fêmea da família Fanniidae, portando 10 ovos no lado esquerdo do abdômen.

\section{Abstract}

One female of Fannia sp. carrying eggs of Dermatobia hominis was captured on a bovine using an entomological net at the Seropedica county, state of Rio de Janeiro. The mass containing ten eggs was fixed on left side of the vector abdomen.

Keywords: Dermatobia hominis; berne; vector; Fannia sp.

* Curso de Pós-Graduação em Medicina Veterinária - Parasitologia Veterinária, Departamento de Parasitologia Animal, Instituto de Biologia, Universidade Federal Rural do Rio de Janeiro, Km 47 da Antiga Rodovia Rio-São Paulo, 23.890-000, Seropédica, Rio de Janeiro, Brasil. 


\section{Agradecimentos}

À Dra. Denise Pamplona, do Laboratório de Diptera do Museu Nacional. Aos colegas Ricardo Jose Salviano e Wanderleia Cristina de Oliveira.

\section{Referências bibliográficas}

ARTIGAS, P. T., SERRA, R. G. Portadores de ovos de Dermatobia hominis (Linnaeus Jr , 1781). Atualização da lista de foréticos, com enumeração de novos agentes transmissores do berne. Cien. Cult. (Brasil), v. 17, n. 1, p. 21-29, 1965.

BRUM, J. G. W., VIANNA, E. E. S., GENTILINI, F., PINTO, L. S. Fannia punctipennis (Diptera: Fanniidae), vetor de ovos da Dermatobia hominis (Oestridae: Cuterebrinae) em Pelotas. Rev. Bras. Parasitol. Vet., v. 5, n. 1, p. 59-60, 1996.

GUIMARÃES, J. H., PAPAVERO, N., PRADO, A. P. do. As miíases na região neotropical (identificação, biologia, bibliografia). Rev. Bras. Zool., v. 1, n. 4, p. 239-416, 1983.

KASAI, N., SCHUMAKER, T.T. S., DELL-PORTO, A., SALVIA-FILHO, V. Variação sazonal de dípteros capturados em armadilhas de
Magoon modificada, em Santana do Parnaíba, Estado de São Paulo. Rev. Bras. Entomol., v. 34, n. 2, p. 369-380, 1990.

OLIVEIRA, G. P. Distribuição sazonal de dípteros muscóides sinantrópicos, simbovinos e foréticos de Dermatobia hominis L. Jr., em São Carlos, Estado de São Paulo. Arq. Biol. Tecnol., v. 29, n. 2, p. 311-25, 1986.

PALOSCHI, C. G., RAMOS, C. I., SOUZA, A. P. de, BELLATO V. Vetores de ovos de Dermatobia hominis (Díptera: Cuterebridae) no planalto catarinense. In: CONGRESSO BRASILEIRO DE MEDICINA VETERINÁRIA, 19. Belém, 1984.

RIBEIRO, P. B., OLIVEIRA, C. M. B., COSTA, P. R. P., BRUM, J. G. W. Foréticos da Dermatobia hominis (Linnaeus Jr., 1781) (Díptera: Cuterebridae), no Rio Grande do Sul, Brasil. Arq. Bras. Med. Vet. Zoot.,v. 37, n. 5, p. 507-509, 1985.

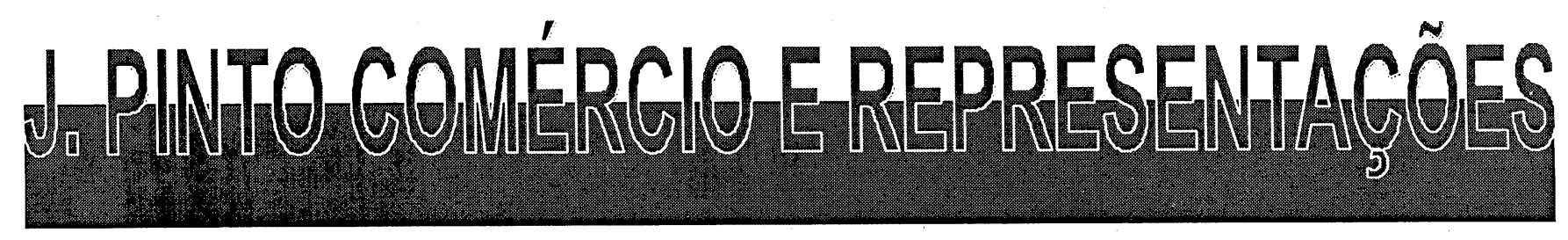

\section{J. Pinto de Macedo - Livraria}

- Especializada em Livros Técnicos Científicos (Nacionais e Estrangeiros)

- Equipamentos Médicos

- Materiais Cirúrgicos em Geral

- Laboratorial

- Medicamentos Veterinários

Rua Vital Brazil Filho, 64 - Parte

(Faculdade de Veterinária)

Niterói-RJ - Caixa Postal 126-048 CEP 24241-970 - Tel.: (21) 710-0229 